\title{
Consideraciones metodológicas sobre el estudio de los núcleos urbanos en la Castilla bajomedieval: notas para un modelo teórico de análisis **
}

\author{
Manuel F. Ladero Quesada *
}

INTRODUCCIÓN

Hace casi ya diez años, en un seminario celebrado en Valladolid sobre aspectos metodológicos de la historia medieval de la Corona de Castilla ${ }^{1}$, el Prof. Estepa señalaba la enorme dificultad que entrañaba esbozar siquiera las líneas generales de un tema tan amplio y con tantos matices como era el de la valoración de los estudios realizados, hasta aquel momento, sobre el mundo urbano de la corona castellana.

No puede sorprender pues que, teniendo en cuenta el tiempo transcurrido, esa dificultad sea considerablemente mayor. Es por ello que nuestra intención en estas breves páginas no sea emular el trabajo del profesor Estepa, quien a pesar de esa advertencia previa sí trazó un sugerente estado de la cuestión; sino sencillamente esbozar algunas re-

** Ponencia presentada en las Jornadas sobre Fuentes y Métodos de la Historia Local, organizadas por el Instituto de Estudios Zamoranos "Florián de Ocampo". Zamora, Octubre de 1990.

* Profesor Titular de H. Medieval. UNED

1. ESTEPA. C., «Estado actual de los estudios sobre las ciudades medievales castellanoleonesas", en Historia Medieval: Cuestiones de Metodología. Univ. de Valladolid, 1982, págs. $27-81$. 
flexiones y consideraciones surgidas al hilo de nuestras propias investigaciones sobre un núcleo urbano concreto: la ciudad de Zamora ${ }^{2}$.

En esta última década y arrancando - por mencionar un hito de todos conocido- de los más de 100 estudios presentados al coloquio sobre la ciudad hispánica celebrado en La Rábida en septiembre de $1981^{3}$, la proliferación de monografías, estudios y artículos de todo tipo y extensión sobre el mundo urbano en los reinos medievales hispanos, ha sido, si se me permite la expresión, "apabullante», de forma tal que resulta realmente difícil no ya mantenerse al día, sino siquiera conocer en profundidad una parte significativa de esta ingente producción historiográfica.

Se puede afirmar, sin demasiado temor a equivocarse, que no existe una sóla ciudad de importancia del reino castellano que no cuente con un estudio global, no es este el momento de entrar en la valoración de la calidad de los contenidos, sobre sus siglos medievales, o, por lo menos, bajomedievales. Es más, muchas de ellas con más de uno y con una buena colección de trabajos más breves o específicos sobre aspectos concretos de su realidad. En cualquiera de los territorios que le componen en el que nos fijemos, ya sea Andalucia, la meseta sur, Murcia, Extremadura, Galicia, la cornisa cantábrica o la meseta norte, creo que es facilmente constatable esta afirmación. Por razones obvias, de espacio y de conocimientos, ceñiré mis comentarios sobre los métodos y los modelos teóricos desarrollados a algunos de los estudios realizados sobre núcleos de la última de las zonas mencionadas.

${ }^{2}$ El núcleo central de esta investigación en nuestro libro Zamora en la época de los Reyes Católicos. Diputación de Zamora, 1991. Otros trabajos complementarios: «Notas sobre las propiedades del cabildo catedralicio de Zamora en el último tercio del siglo XIV (1372-1402)", En la España Medieval V. Univ. Complutense, 1986, págs. 537-549; “Sobre la marginación social en Zamora a finales de la Edad Media: prostitución, pobreza y esclavitud", en Anuario del Instituto de Estudios Zamoranos 1986. Diputación de Zamora, 1986, págs. 213-222; "Apuntes para la historia de los judíos y los conversos de Zamora en la Edad Media (siglos XIII-xv)", en Sefarad, 1988, págs. 29-57; "Aproximación al proceso de formación del patrimonio de la Iglesia zamorana (obispo y cabildo). 1132-1484», en Espacio, Tiempo y Forma (ETF) Revista de la Facultad de Geografía e $H^{a}$ de la UNED, Serie $1 / 1 \mathrm{H}^{a}$ Medieval t. I. Madrid 1988, págs. 249-269; "La participación de Zamora en instituciones de ámbito general de la Corona de Castilla: las Cortes y la Hermandad (siglo xv)", en Anuario de Estudios Medievales 18. Barcelona 1988, págs. 399-408; "La remodelación del espacio urbano de Zamora en las postrimerías de la Edad Media (1480-1520)", en ETF. Serie III $H_{.}{ }^{a}$ Medieval t. II. Madrid 1989, págs. 161-188; "El concejo de Zamora en el siglo xv: aproximación al proceso de monopolio y oligarquización del poder municipal», en ETF Serie III H. Medieval t. III. Madrid 1990, págs. 83-93.

${ }^{3}$ La ciudad hispánica durante los siglos XIII al XVI. 3 Tomos. Univ. Complutense, 1985 y 1987. 
Además de esto, también en los últimos años se han hecho más abundantes, partiendo en gran medida de los trabajos de base sobre ciudades concretas, estudios o artículos de síntesis y reflexión sobre el fenómenos urbano en Castilla bajo muy diversas perspectivas: desde el punto de vista de las relaciones entre las ciudades y el poder real, su participación en instituciones como las Cortes, la plasmación concreta de las diferentes interpretaciones del feudalismo en el estudio de los concejos, las relaciones entre las ciudades y el medio rural, síntesis sobre algún aspecto concreto de la realidad urbana basadas en la comparación de varios núcleos... Son algunas de estas perspectivas.

Parece pues que con el nivel alcanzado por la investigación de la problemática urbana de la Castilla bajomedieval, es factible, y tal vez pueda resultar de cierta utilidad, intentar establecer un modelo genérico que aspire a contemplar los aspectos que, al menos de un modo ideal, deberían ser abordados en el estudio de una ciudad castellana bajomedieval. Teniendo en cuenta siempre que se trata de un modelo teórico condicionado, en primer lugar y de modo decisivo por las fuentes disponibles $y$, en segundo término por los objetivos que se pretendan alcanzar y las premisas ideológicas y metodológicas que informen la investigación.

\section{LOS ELEMENTOS DE BASE}

\subsection{La génesis del núcleo urbano}

Un primer bloque o apartado debería estar dedicado al origen de la ciudad objeto del estudio, amalgamando los primeros datos de la investigación -independientemente de que éstos sean inéditos o no- con un esfuerzo de reflexión. Tras unas breves, pero en ocasiones imprescindibles, precisiones de carácter geográfico, cualquier punto de partida puede ser válido; podemos arrancar, por ejemplo, de los planteamientos clásicos sobre el origen de las ciudades en la Europa medieval, o también, de los argumentos surgidos en el debate producido en el seno de la historiografía marxista. Pero siempre teniendo muy presente que en el territorio peninsular el surgimiento y desarrollo de los núcleos urbanos se encuentra indisolublemente ligado al proceso de repoblación. Además, como es lógico, para muchas ciudades habrá que valorar de forma prioritaria su reciente pasado islámico $\mathrm{y}$, en otros casos, las huellas de momentos históricos anteriores. 
Pero en cualquier caso, la ocupación de tierras y su posterior e inmediata repoblación, fueron la ocasión de aplicar fórmulas y modelos de organización económica y social que, entre otras cosas, son el reflejo del estadio de evolución de la sociedad repobladora y de los intereses concretos de sus distintos agentes, ya sea la monarquía, la nobleza laica o eclesiástica o el mismo campesinado en sus diversos escalones de libertad individual o colectiva.

En términos generales, cabe decir que en la producción historiográfica reciente es este un aspecto bastante descuidado, sobre todo en aquellos estudios que centran su atención en lo siglos bajomedievales. Por tanto sería de desear que en los futuros estudios sobre núcleos urbanos se subsanase esta carencia y sus autores echasen su cuarto a espadas en este necesario proceso colectivo de reflexión sobre el origen de las ciudades castellanas porque, desde mi punto de vista, no cabe entender que los estudios sobre ciudades adquieran unas características propias de la «historia urbana» en los tiempos bajomedievales. Por el contrario, la historia urbana medieval, independientemente del período específico al que se refiera, debe ser entendida como el estudio de la evolución de esa ciudad y sus gentes desde su génesis ${ }^{4}$.

\subsection{La evolución posterior}

Un segundo bloque estaría dedicado a la explicación de lo que comienza a ocurrir en la ciudad una vez que hemos analizado los condicionantes y circunstancias de su origen. Deberemos ocuparnos de su desarrollo urbanístico: de las sucesivas ampliaciones de su recinto y su paulatino proceso de densificación, del desarrollo de su red viaria, etc. El proceso de formación y delimitación de su término y las formas de adquisición del mismo, también deberán ser un objeto importante de estudio.

Igualmente deberemos prestar atención a los aspectos demográficos, por ejemplo, los sucesivos aportes al poblamiento inicial y el paulatino crecimiento del contingente humano, los fenómenos migratorios y sus flujos, los efectos demográficos de los períodos de crisis, la importancia poblacional de las minorías étnicas o, en último término, la cuantificación de la población para la época que constituya el núcleo central de nuestro estudio.

\footnotetext{
${ }^{4}$ Una idea muy similar expresa EstepA, C., ob. cit., pág. 29.
} 
Seguidamente será preciso al menos esbozar la geografía socioeconómica de la ciudad; es decir, la ubicación de los distintos barrios, los lugares de habitación fundamentales de los distintos grupos sociales, la localización de los centros neurálgicos de las actividades económicas específicamente urbanas, la localización espacial de las minorías religiosas, la explicación de los mecanismos o ámbitos de agrupación de la población (collaciones, parroquias, etc.). Sin olvidar que esta geografía socioeconómica debe alcanzar también a los lugares de la tierra, tanto en la perspectiva de su relación con la ciudad, como desde una perspectiva propiamente interna si la documentación lo permite.

Por último, si no se hizo ya anteriormente, será necesario abordar la cuestión desde un punto de vista jurídico en una doble vertiente: por un lado, los derechos y libertades de los ciudadanos, es decir, su condición jurídica, los fueros y reglamentos por los que se rigen, etc. Por otro lado, la condición jurídica de la propia ciudad, es decir, si es de realengo o de señorío (sea éste laico o eclesiástico) y, consiguientemente, la distribución de jurisdicciones que en ella puedan producirse. Ésta era una de las líneas de investigación que, a juicio de Estepa, requerían una profundización y esa demanda, para el ámbito castellano-leonés, ha tenido respuesta en numerosas monografías tanto para concejos de realengo (Burgos, Valladolid, Segovia, Soria, Zamora. Véase nota bibliográfica), incluso contamos ya con un estudio general sobre esta jurisdicción ${ }^{5}$, como de señoríos (Alba de Tormes, Palencia, Benavente... Véase tb. nota bibliográfica). En cualquier caso, no conviene perder nunca de vista el tratamiento de este aspecto.

Una vez hecho todo esto, puede decirse que ya tendremos definidos y analizados lo que Fuente Pérez, en su estudio sobre Palencia, califica como "elementos de base" que nos ponen en situación propicia para emprender el estudio de la ciudad en un momento cronológico concreto; en este caso, los siglos bajomedievales.

\section{LAS TRES DIMENSIONES BÁSICAS DE UN ESTUDIO DE HISTORIA URBANA BAJOMEDIEVAL}

Un estudio de historia urbana bajomedieval debe ser abordado, desde mi punto de vista, al menos desde tres dimensiones o perspectivas

${ }^{5}$ Clemente Ramos, J., Estructuras señoriales castellano-leonesas. El Realengo (siglos XI-XIII). Universidad de Extremadura. Cáceres 1989. 
de análisis. En primer lugar, la descripción de las estructuras económicas sobre las que se sustenta el núcleo urbano; en segundo término, el estudio de la sociedad, cuestión sobre la que convendrá puntualizar algunos extremos; por último, el acercamiento a su dimensión institucional, tanto interna como desde la perspectiva de su relación con otros poderes.

\subsection{La dimensión económica}

Por lo que se refiere a la primera de estas dimensiones, cabe decir que, en cierto modo, las ciudades se encuentran definidas por la actividad económica que se desarrolla en su seno, la cual les confiere una condición de centros activos con respecto a un territorio circundante más o menos amplio y básicamente rural que, sin embargo, sigue configurándose como el pilar fundamental sobre el que se sustenta la supervivencia y crecimiento de la mayoría de los núcleos urbanos.

Es por ello que parezca imprescindible inicialmente el detener nuestra atención en ese entorno rural y fijarse en tres cuestiones básicas, según el esquema planteado por el Profesor Monsalvo en su estudio sobre Alba de Tormes que, en mi opinión, compendia espléndidamente los elementos claves de este apartado. Primeramente, la organización y unidades básicas del paisaje rural, es decir, algo más que la simple descripción formal del terrazgo. Lo segundo, la conceptualización de las relaciones sociales y las formas de propiedad sobre la tierra. $Y$, por último, las formas y mecanismos de explotación de la tierra.

De todos modos, creo que conviene advertir que nuestra perspectiva a la hora de abordar el entorno rural debe ser claramente urbana. Me explico, quiero decir que, a mi modo de ver, la finalidad última de la historia urbana es la propia ciudad: el recinto urbano en sí y sus habitantes; de esta forma, analizaremos el medio rural en tanto en cuanto repercute o incide sobre la vida urbana y no como objeto de estudio en sí mismo.

De todos es conocido que el despertar económico de las ciudades castellanas a la actividad artesana y mercantil tiene lugar a lo largo del siglo XIII de una forma generalizada. Por tanto, resulta imprescindible una aproximación lo más completa posible a estas funciones proverbialmente urbanas en los siglos bajomedievales. 
Por lo que se refiere a la primera de ellas, será preciso conocer las estructuras organizativas del trabajo artesano, es decir, los gremios y las cofradias y los elementos individuales ajenos a ambos tipos de instituciones. Ésta es una de las líneas de investigación que en el mencionado seminario el Profesor Estepa sugería como prioritarias. Hay que decir que, aunque de un modo todavía incompleto, se han producido notables avances; un buen ejemplo lo constituyen las excelentes páginas que, para el caso de Segovia, ha dedicado a la cuestión la profesora Asenjo.

Otro aspecto que no conviene dejar de lado es el papel que la monarquía, sobre todo para la época de los Reyes Católicos, va a jugar en la organización y reglamentación de estas actividades. Por último, habrá que detenerse en la producción manufacturera de la ciudad en sí misma, en su volumen, en su grado o tendencia a la especialización, en los precios de venta y los ámbitos de comercialización, en la cuantificación de la población artesana, en las disputas internas si las hubiere, en la normativa concejil referida a estas actividades, etc.

La actividad comercial o mercantil es, sin duda, una faceta relevante de la vida urbana que precisa de un análisis singularmente detenido. Un aspecto inicial y básico de esta aproximación debe ser la investigación sobre el comercio de corto radio, es decir, la actividad comercial que tiene lugar preferentemente en el recinto urbano y en su entorno rural más inmediato. En segundo término, la localización espacio-temporal de ese tráfico mercantil, o sea, los lugares y momentos en que alcanza un mayor relieve en la vida de la ciudad: los días de mercado semanal y las ferias si es que se celebran, su duración, su continuidad en el tiempo, las franquicias de que gozan los que a ellos acuden y los productos que en ellos se intercambian, y también, si ello es posible, la cuantificación del volumen de esos intercambios y su dimensión dineraria.

Un tercer nivel de estudio tiene mucho que ver con la dimensión institucional de la ciudad, sin embargo, creo que es este el lugar más indicado para abordarlo. Me refiero a la intervención de la autoridad política concejil en este aspecto concreto de la vida ciudadana. Habrá que analizar desde la fiscalidad concejil que grava el comercio, hasta el estudio pormenorizado de los agentes de esta intervención (fieles, sobrefieles y otros oficiales): sus derechos y obligaciones, las condiciones para acceder a los cargos, etc. Será preciso también contemplar los mecanismos de control concejil sobre pesas, medidas y precios y, en general, la legislación municipal elaborada para vigilar y encauzar adecuadamente el desarrollo de la actividad comercial. 
Por último, si el rango y la importancia del núcleo objeto del estudio asi lo requieren porque, en mayor o menor medida, participa en él, habria que detenerse en el papel del comercio de largo radio de acción en la vida de la ciudad. Procurando ubicarla, al menos de un modo aproximado, en el lugar que la corresponda dentro de lo que podríamos denominar "geografía económica de las ciudades castellanas". Un aspecto en el que, claro está, también entraría el estudio de los ciudadanos agentes o participantes en esta actividad, sean pequeños o grandes comerciantes, y sus mecanismos de financiación.

Cabría terminar este apartado reflexionando sobre lo que, una vez contemplado todo lo anterior, podemos denominar «las claves de la política comercial del concejo", es decir, cuestiones tales como: el grado de proteccionismo, ¿a quién beneficia y a quién perjudica la legislación que de él emana?, ¿se trata de una política providencialista, o existe en ella un cierto grado de planificación?. Son todas ellas preguntas que, al menos, requieren un cierto esbozo de respuesta aunque sea desde el plano de la mera hipótesis y hay que decir que, en la mayoría de las monografías recientes sobre ciudades castellano-leonesas, esta preocupación está presente.

\subsection{Precisiones sobre el análisis de la estructura social}

Decía antes que la segunda dimensión del estudio, el análisis de la sociedad urbana, requería de algunas puntualizaciones que se refieren a la perspectiva que adoptemos para llevar a cabo dicho análisis. Lo que habitualmente encontramos en la mayoría de trabajos de conjunto sobre un núcleo urbano concreto, es un capítulo, apartado o epígrafe dedicado exclusivamente a ella, en el que se estudian y describen los distintos sectores o grupos ciudadanos, la permeabilidad o movilidad social, el surgimiento y consolidación de los grupos oligárquicos, los diferentes escalones en los que se desglosa lo que genéricamente conocemos por común, los enfrentamientos entre linajes o bandos, la marginación social - las minorías étnicas 0 , incluso, en el caso de los núcleos en que su importancia es relevante, un acercamiento al estamento eclesiástico. Por señalar sólo alguno de los contenidos más frecuentes.

No es mi intención manifestar que este planteamiento sea incorrecto, sin embargo, a mi modo de ver presenta algunos inconvenientes y especialmente uno: que se corre el riesgo de contemplar la sociedad urba- 
na como una sucesión de compartimentos estancos, algo inerte que se disecciona sin relacionarlo de una forma clara con las realidades que le dan vida, esto es, las realidades económicas y las realidades políticoinstitucionalés de la ciudad. Es por ello que me parezca más util y expresivo un análisis o acercamiento indirecto, o si se quiere dinámico, a la sociedad a través de la contemplación de la actuación y participación de los diferentes grupos ciudadanos en esas otras dimensiones que antes mencionaba, y que son las que les definen como tales grupos. Ciertamente hay que asumir que esta forma de aproximación conlleva un riesgo añadido, el hecho de que probablemente pueda resultar menos didáctico, o si se quiere más confuso para el lector al que se obliga a un esfuerzo suplementario, ya que deberá extraer del análisis realizado sobre esas otras realidades el esquema social que de ellas se deriva.

En cualquier caso, es evidente que sea cual sea el método de aproximación que se utilice, el conocimiento de la estructura social se hace imprescindible en cualquier estudio de historia urbana. Más adelante me referiré a algunos otros aspectos o líneas de investigación sobre los que, a pesar de que ya contamos con un número considerable de trabajos que pueden servirnos de modelo, cabría profundizar para lograr un mejor conocimiento de las sociedades urbanas bajomedievales, y que se sitúan en un plano diferente al de la mera descripción utilitaria de las mismas.

\section{3. La búsqueda de los rasgos institucionales específicos de cada núcleo}

Llegados a este punto, sólo restaría ocuparse de la tercera de las dimensiones que al comienzo señalaba: el marco institucional; o lo que es lo mismo, las estructuras políticas y administrativas, judiciales y hacendísticas que determinan el ritmo de la vida urbana.

No creo que sea necesario detenerse demasiado en este punto. Un buen número de monografías elaboradas en las dos últimas décadas nos muestran excelentes modelos de estudio sobre la estructura concejil y su funcionamiento. Cabría, sin embargo, una puntualización —o si se quiere, advertencia-, en la línea de lo que el profesor Martín señalaba en un seminario sobre tendencias en historia celebrado hace algún tiempo en La Coruña ${ }^{6}$, cuando decía:

"Martín Rodríguez, J. L., "Historia de la Edad Media", en Tendencias en Historia. Encuentro en la Univ. Int. Menéndez Pelayo. Betanzos 1988, págs. 27-33. Especialmente pág. 31. Madrid, CSIC, 1988. 
"La historiografía francesa generalizan a partir de casos particulares y aquí partiendo de las generalizaciones se aplican éstas a casos concretos'».

Y esto no sólo porque, como el mismo Martín decía más adelante, se cuenta en cada caso con fuentes diferentes, sino porque además fenómenos aparentemente similares en todas partes no sólo se producen en momentos cronológicos distintos, sino que además pueden obedecer a factores diferentes como consecuencia de estructuras sociales diferenciadas por sus propias peculiaridades, por lo que es imposible aplicar de. una forma mimética los modelos ya conocidos. Pongamos un ejemplo expresivo: la instauración del Regimiento; no existe una identidad absoluta entre el surgimiento del mismo en ciudades como Burgos y Zamora, y no digamos si comparamos estos casos con los de ciudades de señorío o ciudades que cuentan con otros órganos colegiados o asamblearios con influencia en la esfera del poder local, como los cabildos de jurados o los gremios o bandos caballerescos. Lo mismo cabría decir si nos fijamos en los avatares del intervencionismo regio en cada ciudad: nos resultará muy difícil encontrar dos casos idénticos.

Así pues, sin que ello signifique en absoluto negar la existencia de numerosas semejanzas y similitudes entre los núcleos urbanos de la Corona de Castilla, hay que procurar descubrir los rasgos específicos del desarrollo y funcionamiento del poder local en cada caso concreto.

\section{LA NECESIDAD DE PROFUNDIZAR EN ALGUNAS LINEAS DE INVESTIGACIÓN}

Hasta aquí hemos venido describiendo lo que, a nuestro modo de ver, debe sin duda constituir el núcleo fundamental de una investigación sobre historia urbana. Quedaría ahora sugerir algunas ideas o líneas de investigación en las que se hace precisa una profundización para un mejor conocimiento de la realidad urbana medieval. Son vías de aproximación que se sitúan más en el terreno de lo ideológico o mental que en el plano de la descripción de lo que podríamos denominar estructuras jurídico-materiales.

Por expresarlo de un modo más riguroso, podemos decir que se trata de perspectivas de análisis encuadradas dentro de lo que habitualmente definimos como Antropología Histórica, una materia en la que 
nuestros colegas de allende los Pirineos (especialmente italianos y franceses) están, en muchos aspectos, poniendo punto final a sus investigaciones, mientras que aquí apenas hemos dado los primeros pasos. Me refiero a asuntos tales como la historia de la familia y el parentesco, la vida privada, la alimentación, la cultura popular, etc. Cuestiones todas en las que, a pesar de disponer ya de algunos valiosos trabajos, aun nos queda mucho por saber, especialmente en la esfera de la vida urbana.

Los problemas surgen a la hora de aproximarse a toda esta temática. La mayoría de los historiadores medievalistas españoles, quizás debido a una distorsionada asimilación de los fundamentos teóricos de las escuelas historiográficas con mayor vigencia actualmente (Annales, materialismo histórico), hemos dejado de lado algunos géneros históricos que podríamos definir como clásicos, y que, hoy por hoy, más que géneros históricos en sí mismos deberían recibir la consideración de «otros métodos de aproximación histórica», insertos en el común objetivo de lograr una historia total. Me refiero, en el caso concreto de la historia familiar o del parentesco, a métodos tales como la biografía, la genealogía, la onomástica o la prosopografía ${ }^{7}$.

En muchas ocasiones las fuentes documentales no permiten el desarrollo de este tipo de géneros, pero no siempre es así. Por ejemplo, y refiriéndonos en concreto a la ciudad de Zamora, quizás sea posible hacerlo en algunos casos; contamos, creo, con material suficiente para abordar un estudio amplio de la familia que da nombre a la institución que hoy nos acoge: los Docampo. Disponemos de un bagaje de información considerable sobre el cabeza de esta familia en la época de los Reyes Católicos, el regidor García Docampo, que incluye también su testamento ${ }^{8}$. Igualmente conocemos varios árboles genealógicos descendentes desde la aparición del apellido y del señorío de la familia en las postrimerías del siglo XIV hasta bien entrada la Edad Moderna ${ }^{9}$, que nos pueden permitir el seguimiento del proceso de expansión y afianzamiento del linaje en la sociedad zamorana. Por otro lado, un estudio onomástico de estas genealogías nos permitirá abordar un asunto de indudable interés y escasamente atendido en la publicística reciente, me refiero a la

7 Buena prueba del creciente auge de estas líneas de investigación, es el hecho de que en el recientemente celebrado (Madrid, agosto de 1990) $17 .^{\circ}$ Congreso Internacional de Ciencias Históricas, se dedicasen varias sesiones de la sección de Metodología a estas cuestiones, con valiosas aportaciones de historiadores de todo el mundo.

${ }^{8}$ Real Academia de la Historia. Col. Salazar M-61, fols. 182-185.

${ }^{9}$ Real Academia de la Historia. Col. Salazar D-25, fol. 215v, D-32, fol. 165, D-33, fol. 76. 
cuestión de los hijos ilegítimos, de su destino y de su papel en el seno de la estructura familar ${ }^{10}$.

Igualmente, podremos valorar el papel de las mujeres en la concertación de alianzas con otras familias y en el afianzamiento de la estrategia familiar, no sólo desde el punto de vista económico, sino también desde la óptica del prestigio social. Por ejemplo, sería interesante profundizar en las razones que impulsan a Doña Beatriz Docampo, hermana del citado regidor, a fundar el monasterio de Santa Marina de Zamora en las postrimerías del siglo $\mathrm{xV}^{11}$.

También el estudio de los testamentos no sólo servirá para trazar la trayectoria económica del grupo familiar, sino también para poder tener conocimiento de cuestiones relacionadas con la mentalidad, la religiosidad o la actitud ante la muerte que, probablemente, puedan ser extrapolables al conjunto de la oligarquía zamorana.

Por último, un intento prosopográfico o de comparación con los datos de que disponemos sobre personajes de otras familias relevantes de Zamora, quizás nos pueda ayudar a conocer mejor la estructura de los grupos urbanos dominantes, sus diferencias de criterio, sus posicionamientos en ocasiones diferentes ante los asuntos de la política general del reino o de los asuntos internos del concejo. Y también, por qué no, las similitudes y las diferencias en sus hábitos de comportamiento cotidiano, tal vez derivadas de las distintas causas de su ascenso social.

Igualmente un estudioso de la historia urbana debería dirigir su atención hacia otros asuntos que, con frecuencia, se dejan de lado o apenas se esbozan. Tal es el caso de cuestiones tales como la educación, sus métodos y ámbitos, o el significado de los libros en los medios urbanos que, en general, son poco conocidas, si bien es cierto que las posibilidades que ofrece la documentación suelen ser bastante limitadas. Así, y ejemplificando de nuevo en Zamora, apenas pueden indicarse algunas informaciones deslabazadas, como que se documenta la presencia de un Maestro de Gramática a sueldo del Concejo o que los hijos de las familias poderosas estudiaban en los monasterios de la ciudad (especialmente en el monasterio jerónimo de Montamarta), sin embargo, muy poco podemos señalar sobre el alcance social de esta enseñanza o de su

10 Para una excelente visión de conjunto sobre «los otros» en la historia, véase: BENITO Ruano, E., De la Alteridad en la Historia. Real Academia de la Historia. Madrid 1988.

11 Archivo Histórico Nacional. Clero-Pergaminos. Carpeta 3.583, docs. 1 y 3. 
influencia en la vida cotidiana de los niños, o del prestigio social del mencionado maestro de gramática ${ }^{12}$.

Algo similar ocurre con lo relativo a los libros; sabemos que en Zamora se instaló hacia 1482 el impresor Antón de Centenera. Conocemos con quién se casó, donde vivía e incluso donde se conservan algunas de las obras salidas de su taller ${ }^{13}$; pero muy poco más, preguntas tales como si tenía una especial consideración social por su actividad o era visto como un simple artesano, o si la pequeña nobleza urbana gustaba de poseer o leer libros a semejanza de algunos integrantes de la alta nobleza, no nos es posible contestarlas. Es obvio que si llegamos a conocer las respuestas, tendremos un conocimiento mucho más profundo de la sociedad zamorana del siglo XV.

Para terminar podría sugerirse otra línea de investigación que requiere todavía un importante impulso. Me refiero a un mejor conocimiento de lo que de una forma amplia podríamos denominar «cultura popular», incluyendo en este concepto la visión de la vida cotidiana de los habitantes de las ciudades y todos los factores que la conforman: las celebraciones públicas (corridas de toros, ajusticiamientos, recepción de grandes personajes en la ciudad, acontecimientos de carácter mercantil -ferias- o bélico, etc.), las fiestas y acontecimientos privados o familiares (bodas, bautizos, defunciones y todo lo que ello conlleva de visión del mundo, de sentimientos ante el dolor, la enfermedad o la muerte, de concepciones morales...), y también el "ambiente urbano» (lo que Adeline Rucquoi denomina «ideología urbana»: la forma en que sus vecinos se conciben a sí mismos y piensan de su ciudad).

Como señalaba antes, la profundización en estas cuestiones suele ser ardua, dado lo poco abundante y propicio de las fuentes; sin embargo, en ocasiones tanto la lectura de la literatura de la época ${ }^{14}$, como una relectura de la documentación utilizada prioritariamente para otros aspectos del estudio, pueden procurarnos datos de suma utilidad para el tratamiento de estas líneas de análisis que acabo de señalar.

${ }_{12}$ Archivo General de Simancas. Consejo Real, ley. 49 F. 5-Il. Cuentas del mayordomo del Concejo, años 1484 y 1485.

${ }_{13}$ Archivo General de Simancas. Registro General del Sello. Marzo 1494, f. 5 y Mayo de 1494 f. 3.

${ }_{14}$ Un buen ejemplo de la utilización de textos literarios para el análisis de la sociedad en el reciente trabajo de LADERo QUESADA, M. A., "Aristócratas y Marginales: aspectos de la sociedad castellana en la Celestina", en Espacio, Tiempo y Forma. Serie III, $t$. 3 . UNED. Madrid 1990, págs. 95-120. 
Concluyo ya con una última consideración o, más exactamente, propuesta. Creo que con el nivel alcanzado en la investigación y publicística sobre la vida urbana en la Corona de Castilla a lo largo de los siglos medievales, se hace absolutamente necesaria la elaboración de una síntesis general de historia urbana de los territorios en ellas comprendidos, que amalgame lo ya conocido con todo lo que puedan aportar nuevos estudios en los que se contemplen, entre otras, las líneas de investigación a las que nos hemos referido en esta ponencia.

\section{NOTA BIBLIOGRÁFICA}

Esta ponencia es fruto de las reflexiones surgidas en la elaboración de nuestra propia investigación sobre la ciudad de Zamora (ver nota 2) y de la lectura de numerosos trabajos sobre la problemática urbana y concejil que no es posible reseñar aquí. (Para una información bibliográfica reciente, véanse los excelentes trabajos y reflexiones reunidos en las Actas del II Congreso de Estudios Medievales organizado por la Fundación Sánchez Albornoz en León en septiembre de 1989 (Madrid 1990): Concejos y ciudades en la Edad Media Hispánica).

Como señalaba antes, este ponencia se ciñe fundamentalmente al ámbito castellano-leonés, es por ello que parezca obligado citar algunas obras consultadas con mayor asiduidad para la elaboración de la misma.

Montalvo Antón, J. M., El sistema político concejil. El ejemplo del señorío medieval de Alba de Tormes y su Concejo de villa y tierra. Salamanca 1988. AsENJo GonZÁlez, M., Segovia. La ciudad y su tierra a fines del Medievo. Segovia 1986. Rucquol, A., Valladolid en la Edad Media. Valladolid 1987. Bonachía Hernando, J. A., El Concejo de Burgos en la Baja Edad Media (1345-1426). Valladolid 1978. Esteban Recio, A., Palencia a fines de la Edad Media. Una ciudad de señorío episcopal. Valladolid 1989. FuENTE Pérez, M. ${ }^{a}$ J., La ciudad de Palencia en el siglo xv. Aportación al estudio de las ciudades castellanas en la Baja Edad Media. Madrid 1989. Diago HeRnANDo, M., La Extremadura soriana y su ámbito a fines de la Edad Media. (Tesis Doctoral). Madrid 1990. CASAdo Alonso, H., Señores, mercaderes y campesinos. La comarca de Burgos a fines de la Edad Media. León 1987. HeRnández VICENTE, S., El concejo de Benavente en el siglo $x \mathrm{~V}$. Zamora 1986. 